\title{
Impact of Various Dry-Aging Methods on Meat Quality and Palatability Attributes of Beef Loins (M. longissimus lumborum) from Cull Cow
}

\author{
Derico Setyabrata ${ }^{1}$, Siwen Xue ${ }^{1}$, Kelly Vierck ${ }^{2}$, Jerrad Legako², Paul Ebner ${ }^{1}$, \\ Stacy Zuelly ${ }^{1}$, and Yuan H. Brad Kim* \\ ${ }^{1}$ Department of Animal Sciences, Purdue University, West Lafayette, IN, 47907, USA \\ ${ }^{2}$ Department of Animal and Food Science, Texas Tech University, Lubbock, TX, 79409, USA \\ *Corresponding author. Email: bradkim@purdue.edu (Yuan H. Brad Kim)
}

\begin{abstract}
The objective of this study was to determine the effect of various dry-aging methods on meat quality and palatability attributes of cull cow beef loins. Paired bone-in loins ( $m$. longissimus lumborum) from 13 cull cow carcasses (Holstein, $42+$ mo) were obtained at $5 \mathrm{~d}$ postmortem, divided into 4 equal sections, and randomly assigned into 4 aging methods (wet-aging [WA], conventional dry-aging [DA], dry-aging in water-permeable bag [DWA], and ultraviolet light dry-aging [UDA]). The beef sections were aged for $28 \mathrm{~d}$ at $2^{\circ} \mathrm{C}, 65 \%$ relative humidity, and $0.8 \mathrm{~m} / \mathrm{s}$ airflow. Following aging, surface crusts and bones were removed, and loin samples were collected for the meat quality, microbiological, and sensory analyses. Results indicated that all dry-aged loins had greater moisture and trimming loss compared with WA ( $\mathrm{P}<0.05)$, while DWA had lower loss than DA and UDA $(\mathrm{P}<0.05)$. No differences in shear force, cook loss, or both lipid and protein oxidation across all treatments were observed $(\mathrm{P}>0.05)$. Among all treatments, DWA exhibited the least color stability indicated by rapid discoloration observed in the sample, while UDA had color attributes comparable with WA throughout the whole display. Microbial analysis indicated that UDA had lower microbial concentration on the surface than the other samples $(\mathrm{P}<0.05)$. The consumer panel analysis found that all loins were acceptable, and the trained panel analysis indicated that DA loins decreased sourness and animal fat flavor $(\mathrm{P}<0.05)$ and had a trend of decreasing oxidized flavor $(\mathrm{P}=0.07)$. The results indicate that dry-aging can potentially be utilized as an effective natural process by nullifying some of well-known off-flavor attributes associated with cull cow beef while not compromising other meat quality attributes or microbiological shelf life.
\end{abstract}

Key words: dry-aging, cull cow, ultraviolet light, sensory attributes, microbial attributes Meat and Muscle Biology 6(1): 13025, 1-15 (2022)

doi:10.22175/mmb.13025

Submitted 31 July 2021

Accepted 9 September 2021

\section{Introduction}

Cull cows account for up to $19 \%$ of the total beef cattle harvested in the United States (USDA, 2019), playing an important role in fulfilling the beef demands in the United States (about 10\% of beef supply). As cows are often culled from the herd at an older age (42 mo or higher), beef from mature animals is known to have inferior palatability, such as decreased tenderness and undesirable flavor (Gredell et al., 2018). Additionally, cull cow diets are often based on low-energy forages, decreasing the flavor desirability by the consumer (Woerner, 2010). As such, the majority of cull cow beef, however, was utilized as ground beef or manufacturing products rather than retail whole muscle cuts (Xiong et al., 2007), thus placing the products in a low-value beef category compared with conventional beef from young animals.

Multiple postharvest techniques, such as salt injection (Morgan et al., 1991; Diles et al., 1994) and blade tenderization (Obuz et al., 2014), have been developed and are currently utilized as a postharvest 
intervention to negate these palatability issues. However, the current postharvest processes may be less favorable to consumers, as there is an increasing demand for natural and minimally processed meat products (Verbeke et al., 2010). Thus, there is a need for developing natural/value-adding postharvest processes to improve cull cow meat palatability.

Postmortem aging is a common practice that improves meat quality attributes, wherein considerable improvements in tenderness, juiciness, and/or flavor take place through naturally occurring endogenous enzymatic activities (Kim et al., 2018). In general, aging can be performed in 2 different types; wet-aging (WA; utilizing vacuum packaging) and dry-aging (without packaging materials in a highly controlled environment). Dry-aging specifically has been known to generate unique flavors such as "brown-roasted," "beefy," and "buttery" flavors (Campbell et al., 2001; Setyabrata et al., 2021). In addition to the unique flavors, positive impacts of dry-aging on improvements in tenderness and juiciness have also been reported, making the product more desirable by consumers (Campbell et al., 2001). Furthermore, a recent study by Berger et al. (2018) reported that palatability improvements from dry-aging were identified in low marbled grass-fed beef, suggesting the potential feasibility of utilizing dry-aging as a natural value-adding process for low-quality/low-value products, such as cull cow beef.

Given that dry-aging conditions require exposure of meat to the environment without a protective barrier, a potential risk of microbial contamination of the meat exists. The application of moisture-permeable bags for dry-aging was reported to be effective in minimizing contamination and moisture loss while providing similar dry-aged beef characteristics (Ahnström et al., 2006; Li et al., 2013). Furthermore, ultraviolet (UV) lights have been demonstrated as an effective and affordable method to limit microbial growth (Chun et al., 2010) and could be applied during the dry-aging processing, either through direct exposure of the product to UV light (DeGeer et al., 2009; Smith et al., 2014) or by sterilizing incoming air within the air filter (Warren and Kastner, 1992; Lepper-Blilie et al., 2016). While UV light application has previously been shown to successfully retard the growth of microbial in various applications (Chun et al., 2010; Ganan et al., 2013; Yeh et al., 2018), its impact on dry-aged meat quality development has not been fully studied. Therefore, the objective of this study was to evaluate the effect of dryaging and different aging methods on meat quality, microbiological shelf life, and palatability of beef from cull cows.

\section{Material and Methods}

\section{Sample collection, preparation, and processing}

Paired bone-in beef loins from 13 cull cow carcasses (42+ mo old, C maturity, Holstein, NAMP: 175 , $m$. longissimus lumborum) were collected from a commercial beef plant at $5 \mathrm{~d}$ postmortem. The samples collected were all categorized as USDA utility grade by the plant worker and had a fat cover $<2 \mathrm{~cm}$ in the loin area. Beef loins were vacuum-packed and stored in ice chests during transportation to the Purdue Meat Science and Muscle Biology Laboratory. The samples were immediately processed following arrival in the facility. Prior to any processing, initial microbiological and biochemical samples were individually excised from the loin eye area (anterior portion) from one side of the loins. The loins were then divided into 2 equal length sections, totaling 4 sections from each animal. The sections were then randomly assigned to 4 different aging methods: WA (Clarity Vacuum Pouches, Bunzl Processor Division, Riverside, MO), conventional dry-aging (DA), dry-aging in water-permeable bag (DWA; UMAi Dry Short Loin [Large], UMAi Dry, Minneapolis, MN) and UV light dry-aging (UDA).

The initial $\mathrm{pH}$ value and weight were measured for all beef sections, followed by $28 \mathrm{~d}$ of aging at $2{ }^{\circ} \mathrm{C}, 65 \%$ relative humidity, and $0.8 \mathrm{~m} / \mathrm{s}$ airflow. The UV light treatments were applied twice per day to UDA samples, with a dose of $5 \mathrm{~J} / \mathrm{m}^{2}$ for each UV treatment $(5 \mathrm{~min}$ of exposure per treatment, Philips TUV T8 UVC light, Eindhoven, Netherlands). The UV light was mounted $30 \mathrm{~cm}$ above the samples. The beef sections were rotated weekly to minimize any location variation within the cooler. At the end of aging treatment, the sections were weighed, deboned, and trimmed, separating the dehydrated surfaces (crust) from the inner lean portions, and the trimmed sections were weighed again to calculate the final yield. Samples from both the surface crust and lean portions were collected for microbiological analyses. Postaging $\mathrm{pH}$ values were measured, and sections were cut into steaks $(2.4 \mathrm{~cm}$ thick) for further meat quality analyses, including Warner-Bratzler shear force (WBSF), color stability, water-holding capacity, oxidative stability, and sensory analysis. Except for the 
samples assigned for color and drip loss analyses, all steak samples were individually vacuum packaged and stored in a $-80^{\circ} \mathrm{C}$ freezer until analysis.

\section{pH measurement}

The $\mathrm{pH}$ measurement was performed before and after the aging treatment using a portable meat $\mathrm{pH}$ meter (HI99163, Hanna Instruments, Inc., Smithfield, $\mathrm{RI})$ by directly inserting the probe into 2 different locations of the meat. The $\mathrm{pH}$ meter was calibrated to both $\mathrm{pH} 4$ and 7 standards (Thermo Scientific Orion, ThermoFisher Scientific, Waltham, MA) following the manufacturer's guidelines.

\section{Aging loss, processing loss, and saleable yield}

The weights for each section were collected prior to and after the aging regime to estimate the shrink/ water loss during aging. The final weights of the trimmed lean portions were recorded to calculate the final saleable yield of the products. The losses were presented as percent loss, measuring the loss over the aged sample weight.

\section{Water-holding capacity measurement}

The water-holding capacity was analyzed by measuring both drip loss and cook loss of each sample. All losses were expressed as percent weight loss, measuring the change between the initial and final weight of the samples. The drip loss measurement was conducted using the Honikel drip loss method following the modification by Kim et al. (2017).

The cook loss was performed by cooking the sample until the internal temperature reached $65^{\circ} \mathrm{C}$ using a clamshell grill (Griddler GR-150, Cuisinart, Stamford, CT). The samples were blotted dry using paper towels and weighed before and after the cooking process to estimate the percent weight loss due to cooking. Internal temperature was monitored using a $T$ type thermocouple (Omega Engineering, Inc., Norwalk, CT) connected to an OctTemp 2000 data logger (MadgeTech, Inc., Warner, NH). Following cooking, samples were wrapped using aluminum foil and kept at $4^{\circ} \mathrm{C}$ overnight for WBSF measurement.

\section{Warner-Bratzler shear force measurement}

Following overnight storage, WBSF was measured on the steaks previously used for cook loss measurement. A total of 10 cores $(1.27-\mathrm{cm}$ diameter) parallel to the muscle fiber direction were collected from each steak. The cores were then cut perpendicular to the muscle fiber using a TA-XT Plus Texture Analyzer (Stable Micro Systems, Ltd., Godalming, UK) equipped with V-shaped blade for WBSF measurement. The average peak shear force $(\mathrm{N})$ from the cores was calculated.

\section{Proximate analysis}

Proximate analysis was performed following the protocol described in the AOAC official guidelines (AOAC, 2007). All proximate contents are presented on a wet matter base (\%). Fat content was calculated using the following formula:

$$
\begin{aligned}
& \text { Fat content }(\%) \\
& \quad=100-(\text { Moisture content }+ \text { Protein content }+ \text { Ash content })
\end{aligned}
$$

\section{Display color stability}

At the end of the aging process, one steak from each section was randomly assigned for $7 \mathrm{~d}$ simulated display under continuous light at $2^{\circ} \mathrm{C}$. The samples were placed on a Styrofoam tray with drip soaking pad and overwrapped using oxygen-permeable polyvinyl chloride film (Reynolds Packaging, Green Bay, WI). The steaks were displayed for $7 \mathrm{~d}$ under fluorescent light $(1,800 \mathrm{~lx}$, color temperature $=3,500 \mathrm{~K}$, OCTRON T8 Lamps, Osram Sylvania, Ltd., Markham, Ontario, Canada), and the color and color stability were evaluated daily by both a trained color panelist and instrumental colorimeter.

The panelists $(n=8)$ were trained following the American Meat Science Association meat color guidelines (AMSA, 2012) on lean surface color and discoloration. The panelists were required to pass the Farnsworth-Munsell 100 Hue Test and trained on multiple sessions prior to the study (AMSA, 2012). The surface lean color was scored with a scale of 1 to 8 $(1=$ extremely dark brown red; $2=$ dark brown red; $3=$ moderately dark/brown red; $4=$ slightly dark/ brown red; $5=$ slightly bright red; $6=$ moderately bright red; $7=$ bright red; $8=$ extremely bright red) during the entire display periods. At the same time, surface discoloration was also scored using a scale of 1 to 7 ( $1=$ no discoloration; $2=1 \%-19 \%$ discoloration; $3=20 \%-39 \%$ discoloration; $4=40 \%-59 \%$ discoloration; $5=60 \%-79 \%$ discoloration; $6=80 \%-99 \%$ discoloration; $7=100 \%$ discoloration).

During the $7 \mathrm{~d}$ of display periods, the Hunter MiniScan EZ colorimeter (HunterLab, Reston, VA) was utilized to collect the instrumental color by measuring 
the Commission Internationale de $1^{\prime}$ Eclairage $L^{*}, a^{*}$, and $b^{*}$ on 3 random locations of the surface steak samples on a daily basis. The instrument was calibrated following the manufacturer's guidelines and equipped with $25-\mathrm{mm}$ (diameter) opening prior to any data collection. The illuminant A was used, and the observer was set to standard $10^{\circ}$. Hue angle and chroma value were calculated using the following formulas: hue angle $=\tan ^{-1}\left(b^{*} / a^{*}\right)$ and chroma $=\left(a^{* 2}+b^{* 2}\right)^{1 / 2}$ (AMSA, 2012). At the end of display, steaks were vacuum packaged individually and stored in $-80^{\circ} \mathrm{C}$ for lipid and protein oxidation determination.

\section{Lipid oxidation}

The extent of lipid oxidation for the samples was determined by measuring the lipid oxidation level of the steak samples from day 1 and day 7 of retail display. The lipid oxidation was measured using frozenpowdered samples by conducting the 2-thiobarbituric reactive substances (TBARS) assay described by Setyabrata and Kim (2019). The absorbance was read at $531 \mathrm{~nm}$ using Epoch Microplate Spectrophotometer (BioTek Instruments, Inc.), and TBARS value was expressed as milligrams malondialdehyde/kilograms meat.

\section{Protein oxidation}

The degree of protein oxidation was measured through the estimation of carbonyl content using the same frozen-powdered whole samples utilized for the observation of lipid oxidation. The measurement was performed following the method described by Vossen and De Smet (2015), and the carbonyl content was expressed as nanomole carbonyls per milligram protein (nanomole/milligram protein).

\section{Microbial analysis}

The total aerobic bacteria (aerobic plate count [APC]), lactic acid bacteria (LAB), yeast, and mold concentrations were determined for all treatments and samples collected from lean and crust portions at the end of aging period. Microbial analyses were then conducted following the method described by Berger et al. (2018) with modification. In brief, $5 \mathrm{~g}$ of sample were aseptically collected, placed into a stomacher bag (Whirl-Pak, Madison, WI) with $50 \mathrm{~mL} 0.1 \%$ peptone water (BD Difco, Sparks, MD), and hand stomached for $1 \mathrm{~min}$. The rinsate was collected, serially diluted, and plated for enumeration of viable bacteria. The APC concentration was determined using plate count agar (BD Difco) which were incubated for $48 \mathrm{~h}$ at $37^{\circ} \mathrm{C}$ following inoculation. $\mathrm{LAB}$ were quantified using de Man, Rogosa, and Sharpe agar (BD Difco), which were incubated for $72 \mathrm{~h}$ at $37^{\circ} \mathrm{C}$ under anaerobic conditions generated using anaerobic packs (Oxoid AnaeroGen, ThermoFisher Scientific) following inoculation. Both yeast and mold concentration were calculated using yeast and mold films (Petrifilm, 3M, St. Paul, MN), which were incubated at $25^{\circ} \mathrm{C}$ for $120 \mathrm{~h}$ following inoculation. After each incubation, colonies were counted, and the microbial concentration was expressed as $\log _{10}$ colony-forming units $(\mathrm{CFU}) / \mathrm{mL}$ of rinsate. For both APC and LAB measurement, plates with colonies count below 25 colonies on the lowest dilution were considered as having bacterial concentration below detection limit. For the yeast and mold petrifilms, the detection limit was set at 15 colonies per the manufacturer's recommendation.

\section{Sensory analysis}

Sensory evaluation was conducted using both trained and consumer panelists at Texas Tech University. The research protocol was approved by the Texas Tech Institutional Review Board (IRB\# 2017721). The steak samples collected for the sensory analyses were frozen at $-40^{\circ} \mathrm{C}$ and were shipped using overnight shipping in a Styrofoam cooler. The steaks were thawed for $24 \mathrm{~h}$ at $4^{\circ} \mathrm{C}$ in preparation for the sensory session. All samples were cooked on a clamshell grill (Griddler GR-150, Cuisinart) until the internal temperature reached $65^{\circ} \mathrm{C}$. Following cooking, steaks were cut into $2.4 \times 1 \times 1 \mathrm{~cm}$ cubes, and 2 cubes were served to each panelist. The samples were held in a warmer (Cambro Ultra Heated Holding Pan Carrier, 214UPCH400, Cambro Manufacturing, Huntington Beach, CA) for no longer than 30 min prior to serving. Samples were served under red incandescent light. Panelists were supplied with distilled water, apple juice, and unsalted saltine crackers as a palate cleanser between each sample as well as an expectorant cup, toothpick, fork, knife, and napkin.

Trained sensory panelists. A total of 11 panelists were recruited and trained to detect various beef flavor and palatability characteristics according to the AMSA Sensory Guidelines (AMSA, 2016). The panelists were trained and tested for $4 \mathrm{wk}$ prior to participating in panel evaluation. Panelists were trained to identify the following traits: beef flavor identity, brown/ roasted, bloody/serumy, fat-like, liver-like, oxidized, metallic, fishy, buttery, nutty, earthy/musty, umami, salty, bitter, sour, overall juiciness, and overall 
tenderness. Each scale was anchored at each endpoint and had a neutral midpoint (e.g. $0=$ extremely bland/ dry/tough; $50=$ neither tough/dry nor tender/juicy; $100=$ extremely tender/juicy/intense). The sensory samples were randomly assigned to each sensory session, ensuring that each treatment was represented in each panel. A total of 7 panel sessions were conducted, each having 8 beef samples, except for the final panel, where only 4 samples were served. Samples were prepared and served following the condition previously described.

Consumer sensory panelist and survey. The consumer sensory evaluation was conducted using 130 panelists recruited from the Lubbock, TX, area. The evaluation was conducted in $1 \mathrm{~h}$ sessions with 20 consumer panelists per session, except the final session, which had only 10 panelists. The steak samples were prepared and served following the process previously mentioned. During each session, panelists received an electronic ballot (Qualtrics, Provo, UT) consisting of a demographics questionnaire, 5 sample ballots, and a final survey to determine the panelist's familiarity with dry-aging, their familiarity with beef from dairy cattle, and their willingness to pay for dry-aged product. Each panelist evaluated one warmup sample followed by one sample of each treatment $(n=5)$. Samples were evaluated for flavor, tenderness, juiciness, and overall liking on unstructured 100-point line scales. Scales were verbally anchored at each endpoint and midpoint $(0=$ extremely dislike/extremely tough/ extremely dry; $50=$ neither dislike nor like/neither tough nor tender/neither dry nor juicy; $100=$ extremely like/extremely tender/extremely juicy). Additionally, each panelist was also asked to rate each trait as acceptable or unacceptable and to designate each sample as unsatisfactory, everyday, better than everyday, or premium quality. The term dairy cattle beef was utilized in the survey to represent beef from mature cull cows since it is commonly perceived that dairy cattle are older, and therefore the term might be more familiar to the consumers (Moreira et al., 2021).

\section{Statistical analysis}

This study was a randomized complete block design with 4 different aging treatments as the fixed effect and animal as the random effect. In the microbial analysis, sample source (lean or crust) was added as a fixed effect to consider potential location differences. For the sensory evaluation, panelists and sessions were added as the random effects in the model during analysis. The meat processing and quality data were analyzed using PROC MIXED procedure from SAS 9.4 software (SAS Institute, Inc., Cary, NC). Both trained and consumer sensory panel data were analyzed using PROC GLIMMIX procedures from SAS 9.4 software (SAS Institute, Inc.). Least-squares means for all traits were separated, and the significance level was defined at the level of $\mathrm{P}<0.05$.

\section{Results and Discussion}

\section{Processing loss and saleable yield}

Lower shrink/purge loss was observed for WA samples compared with the dry-aged beef samples, such as DA, DWA, and UDA, as expected $(\mathrm{P}<0.05$, Table 1). Within the dry-aged beef samples, DWA loins had less aging loss than both DA and UDA loins $(\mathrm{P}<0.05)$. Correspondingly, more dehydrated lean surface crusts were trimmed from both DA and UDA loins when compared with DWA loins $(\mathrm{P}<0.05)$. As expected, all dry-aging treatments had a greater total loss compared with WA samples $(\mathrm{P}<0.05)$. Of the dry-aging treatments, the total loss in UDA and DA loins was not different from each other $(\mathrm{P}>0.05)$ but was greater compared with DWA loins $(\mathrm{P}<0.05)$. Accordingly, both DA and UDA loins also had a lower total yield compared with all treatments $(\mathrm{P}<0.05)$.

Dry-aging has been known to induce a considerable amount of aging loss due to the moisture evaporation during the process. In conjunction, the dehydrated surface crust forms as the result of dry-aging, which

Table 1. Effect of different aging treatments on shrink/ purge loss, trim loss, total loss, and total saleable yield of cull cow beef $m$. longissimus lumborum after $28 \mathrm{~d}$ of aging

\begin{tabular}{lccccc}
\hline \hline & $\begin{array}{c}\text { Shrink/ } \\
\text { Purge Loss } \\
(\%)\end{array}$ & $\begin{array}{c}\text { Trim } \\
\text { Loss } \\
(\%)\end{array}$ & $\begin{array}{c}\text { Total } \\
\text { Loss } \\
(\%)\end{array}$ & $\begin{array}{c}\text { Total Loss } \\
\text { without Trim } \\
(\%)\end{array}$ & $\begin{array}{c}\text { Total } \\
\text { Yield } \\
(\%)\end{array}$ \\
\hline WA & $1.17^{\mathrm{c}}$ & $0.00^{\mathrm{c}}$ & $47.78^{\mathrm{c}}$ & $47.78^{\mathrm{b}}$ & $52.22^{\mathrm{a}}$ \\
DA & $12.09^{\mathrm{a}}$ & $5.58^{\mathrm{a}}$ & $56.05^{\mathrm{a}}$ & $50.47^{\mathrm{a}}$ & $43.95^{\mathrm{c}}$ \\
DWA & $7.59^{\mathrm{b}}$ & $3.99^{\mathrm{b}}$ & $50.68^{\mathrm{b}}$ & $46.69^{\mathrm{b}}$ & $49.32^{\mathrm{b}}$ \\
UDA & $12.44^{\mathrm{a}}$ & $6.31^{\mathrm{a}}$ & $54.37^{\mathrm{a}}$ & $46.23^{\mathrm{b}}$ & $45.63^{\mathrm{c}}$ \\
Standard & 0.682 & 0.318 & 1.494 & 1.562 & 1.494 \\
error of & & & & & \\
mean & & & & & \\
$P$ value & $<0.0001$ & $<.0001$ & $<.0001$ & 0.0227 & $<0.0001$ \\
\hline
\end{tabular}

${ }^{\mathrm{a}-\mathrm{c}}$ Different superscript letters indicate a significant difference between the different aging methods $(P<0.05)$.

Different aging treatments: DA = conventional dry-aging; DWA = dryaging in water permeable bag; $\mathrm{UDA}=$ ultraviolet light dry-aging; $\mathrm{WA}=$ wet-aging . 
requires removal prior to sale and/or consumption of the product (Savell, 2008), further increasing the yield loss. In the present study, the lower loss in purge, trim, and total loss exhibited by DWA compared with other dry-aging methods is in agreement with previous studies reported by Ahnström et al. (2006) and Berger et al. (2018). The lower total loss potentially occurred due to additional protection from the dry-aging bag, which may have limited the rate of moisture transfer during the aging process. While dry-aging produces greater loss, the crust generated from the process was demonstrated to have antioxidant and emulsifying capability in other reports (Choe et al., 2020; Xue et al., 2021), indicating the potential of crust as a novel food ingredient and therefore recouping the loss from the dryaging process.

\section{$p H$, shear force, proximate composition, and water-holding capacity}

No differences were observed in initial $\mathrm{pH}$ values across all treatments $(\mathrm{P}>0.05$, data not shown). A significant treatment effect was observed on the final product $\mathrm{pH}$ following the different aging treatments $(\mathrm{P}<0.05$, Table 2). Specifically, DWA loins had lower $\mathrm{pH}$ values compared with all other treatments $(\mathrm{P}<$ $0.05)$. It is possible that the moisture-permeable bag in DWA provided a flourishing environment that could allow microbial growth, as indicated with the high microbial count in DWA loins in the current study. It has been suggested that LAB have a symbiotic relationship with aerobic bacteria and yeast to promote fermentation (Horiuchi and Sasaki, 2012; AdesuluDahunsi et al., 2020) and thus potentially decrease the product $\mathrm{pH}$ due to acid production.

Different aging treatment processes did not affect the WBSF values of the samples $(\mathrm{P}>0.05)$. All the samples were observed to have a shear force value of less than $30 \mathrm{~N}$, indicating that the products could be considered as moderately tender (Smith et al., 2008). Similar results were also reported previously wherein similar shear force values were observed regardless of the aging treatments (Dikeman et al., 2013; Kim et al., 2016; Berger et al., 2018). This observation indicated that the different aging processes within a given extended aging period may not alter the extent of proteolysis, and thus, the instrumental tenderness improvement would be more affected by the total duration period of aging.

Proximate compositions of the meat samples were found to be significantly affected by the treatment applied (Table 2). The dry-aging treatments (DA and UDA) induced excessive dehydration, having lower moisture contents than WA treatments $(\mathrm{P}<0.05)$. The DWA samples, however, had similar amounts of moisture to WA samples $(\mathrm{P}>0.05)$. Similar results were observed by Berger et al. (2018), suggesting that the dry-aging bag could provide additional protection to limit moisture loss during dry-aging, which is in line with the previous observation in aging/shrink loss. Higher protein, fat, and ash (mineral) contents were observed in both DA and UDA $(\mathrm{P}<0.05)$ compared with WA and DWA, potentially due to greater moisture loss, concentrating the content of the product. It is of interest to note that greater concentrations of protein, fat, and ash along with lower moisture contents were observed in UDA samples compared with the other treatments. While very little information is available regarding UV application and its subsequent impacts on fresh beef quality, a previous study on salmon fillets showed that following UV treatments, salmon fillets had a significant temperature increase, likely due to heat introduced by UV light (Ozer and Demirci, 2006). Therefore, it may be possible that heat generated from UV light would induce further moisture loss during the aging.

Table 2. Effect of different aging treatments on $\mathrm{pH}$ value, shear force, proximate content, and water holding capacity of cull cow beef $m$. longissimus lumborum after $28 \mathrm{~d}$ of aging

\begin{tabular}{|c|c|c|c|c|c|c|c|c|}
\hline Treatments & $\mathrm{pH}$ & $\begin{array}{c}\text { Shear Force } \\
(\mathrm{N})\end{array}$ & $\begin{array}{c}\text { Moisture Content } \\
(\%) \\
\end{array}$ & $\begin{array}{c}\text { Protein Content } \\
(\%) \\
\end{array}$ & $\begin{array}{c}\text { Fat Content } \\
(\%)\end{array}$ & $\begin{array}{c}\text { Ash Content } \\
(\%)\end{array}$ & $\begin{array}{c}\text { Cook Loss } \\
(\%)\end{array}$ & $\begin{array}{c}\text { Drip Loss } \\
(\%)\end{array}$ \\
\hline WA & $5.75^{\mathrm{a}}$ & 26.85 & $67.75^{\mathrm{a}}$ & $24.11^{\mathrm{c}}$ & $7.24^{\mathrm{b}}$ & $0.90^{\mathrm{d}}$ & 13.42 & $1.08^{\mathrm{b}}$ \\
\hline DA & $5.74^{\mathrm{a}}$ & 27.99 & $60.12^{\mathrm{b}}$ & $29.48^{\mathrm{b}}$ & $9.02^{\mathrm{a}}$ & $1.38^{\mathrm{b}}$ & 13.83 & $0.90^{\mathrm{b}}$ \\
\hline DWA & $5.64^{\mathrm{b}}$ & 26.74 & $66.33^{\mathrm{a}}$ & $25.00^{\mathrm{c}}$ & $7.51^{\mathrm{b}}$ & $1.16^{\mathrm{c}}$ & 13.73 & $0.74^{\mathrm{b}}$ \\
\hline UDA & $5.74^{\mathrm{a}}$ & 29.70 & $52.89^{c}$ & $35.24^{\mathrm{a}}$ & $10.28^{\mathrm{a}}$ & $1.59^{\mathrm{a}}$ & 12.88 & $1.45^{\mathrm{a}}$ \\
\hline $\begin{array}{l}\text { Standard error of } \\
\text { mean }\end{array}$ & 0.016 & 1.178 & 1.340 & 0.820 & 1.179 & 0.043 & 0.592 & 0.116 \\
\hline$P$ value & $<0.0001$ & 0.076 & $<0.0001$ & $<0.0001$ & $<0.0001$ & $<0.0001$ & 0.575 & $<0.0001$ \\
\hline
\end{tabular}

${ }^{\mathrm{a}-\mathrm{c}}$ Different superscript letters indicate a significant difference between the different aging methods $(P<0.05)$.

Different aging treatments: DA = conventional dry-aging; DWA = dry-aging in water permeable bag; UDA = ultraviolet light dry-aging; WA = wet-aging. 
No difference was observed in cook loss among the different treatments $(\mathrm{P}>0.05)$. All the products exhibited a similar cook loss, ranging from $12.88 \%$ to $13.83 \%$ (Table 2). Similar results were observed and reported in previous studies, wherein no significant differences were observed in water-holding capacity (including cook loss) of meat aged with different aging methods (Laster et al., 2008; Dikeman et al., 2013; Kim et al., 2016; Berger et al., 2018). For the drip loss, greater loss $(\mathrm{P}<0.05)$ was identified in UDA loins compared with all other treatments. However, the magnitude of the differences was very small $(<1 \%)$ and thus would be practically less meaningful.

\section{Display color stability}

No differences in color and color stability of beef samples from different aging treatments were found until $5 \mathrm{~d}$ of display, where the majority of the instrumental color attributes indicate significant changes between the samples $(\mathrm{P}>0.05$; Figure 1$)$. The WA samples displayed a greater lightness $(\mathrm{P}<0.05)$ starting from day 5 until the end of the display compared with all dry-aging treatments. Among the dry-aging methods, UDA loins maintained similar redness, yellowness, hue angle, and chroma value when compared with WA loins throughout the display $(\mathrm{P}>$ 0.05). Both DA and DWA samples had a comparable color stability $(\mathrm{P}>0.05)$, except for redness and hue angle, wherein the DWA samples had lower redness and higher hue angle values $(\mathrm{P}<0.05)$ compared with DA samples and all other treatments.

The results of the visual color observation by trained panelists were in agreement with the instrumental observation, wherein a significant interaction was observed between aging treatment and display period. A decrease was observed along the display period for lean color $(\mathrm{P}<0.05)$. Similar discoloration and lean color were observed at the beginning of display up to day 4 among all samples $(\mathrm{P}>0.05)$. A significant decrease in lean color was observed in DWA samples, which were scored the lowest starting from day 5 of display. At the end of the display, WA loins had the greatest lean color score (indicating greater brightness and redness), followed by UDA, DA, and DWA loins having the lowest lean color score $(\mathrm{P}<0.05$, Figure $2 \mathrm{~A})$. For the discoloration score, a similar result to hue angle result was found, wherein a significant increase was observed from day 5 until the end of display. Both UDA and WA loins had the lowest visual discoloration score, followed by DA and DWA loins having the highest score $(\mathrm{P}<0.05$, Figure $2 \mathrm{~B})$.
The results of the current study provide an additional insight to the color stability of dry-aged products, wherein dry-aged beef products can be displayed in the retail condition without any noticeable discoloration up to $4 \mathrm{~d}$. Among the dry-aged samples, DWA exhibited lower color stability, determined as the most discolored at the end of the display by both trained panel and instrumental measurement. It could be speculated that the additional protection from the dry-aging bag interfered with the drying of the meat surface, slowing the generation of the dehydrated crust on the surface as a physical barrier. This would then allow oxidation to occur through the aging process and thus reduce the color stability. Interestingly, while UV light has been suggested to induce oxidation through photo-oxidation (Jongberg et al., 2017), UDA samples were observed to have color comparable with WA samples. The UDA samples also showed greater color traits among all dry-aged treatments, suggesting that microbial presence could contribute more to the reduction in color stability of dry-aged beef loins.

\section{Oxidative stability}

No significant aging treatment and interaction between aging treatment and display time on both lipid and protein oxidation was found. However, both protein and lipid oxidation were affected by display time $(\mathrm{P}<0.05$, Table 3$)$, shown by increased TBARS and carbonyl values over the display. The result exhibited that dry-aged beef potentially would have a comparable oxidative stability with wet-aged meat product. This could be the result of the dehydrated surface crust that formed on dry-aged beef loins (Berger et al., 2018), which provide some level of protection against oxidative environments, limiting oxygen transfer and light penetration to the product. However, it is of interest to note that there was a trend $(\mathrm{P}=0.068)$ of an increase in carbonyl content in the UDA samples following the display compared with other treatments. This could indicate that although the surface crust might work as a protective layer, a continuous exposure to UV light may still lead to adverse impacts on products, and thus higher dose levels of UV light application could be undesirable for oxidative stability and subsequent off-flavor development.

\section{Microbial analysis}

Initial microbial concentrations prior to any aging treatments for all microbial groups measured were below detection limits (data not shown), indicating similar initial microbial concentrations across the samples. Following $28 \mathrm{~d}$ of aging treatments, a significant 
(a) CIE L*

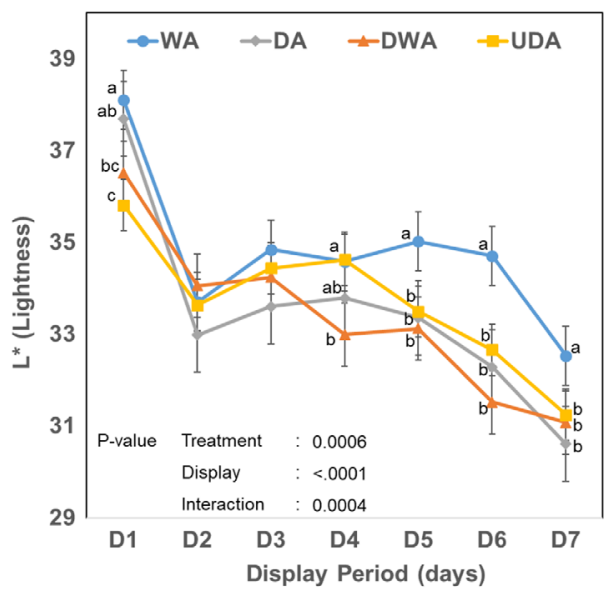

(c) CIE b*

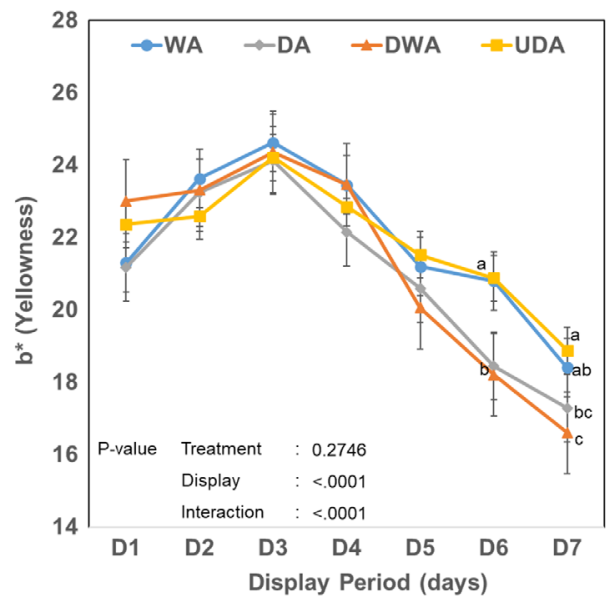

(b) CIE a*

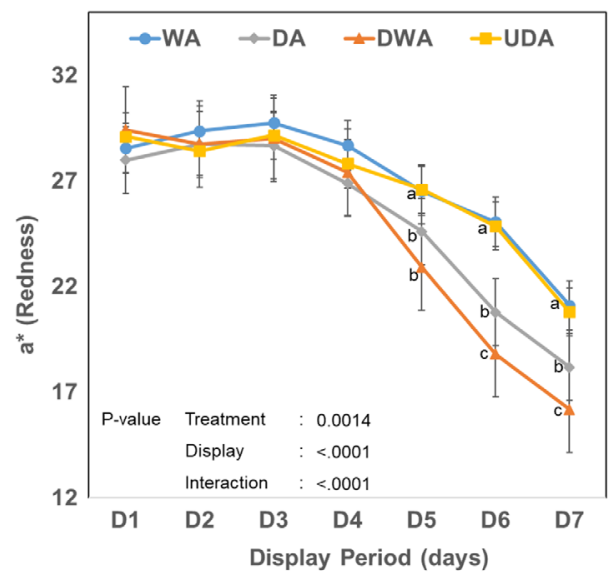

(d) Hue angle

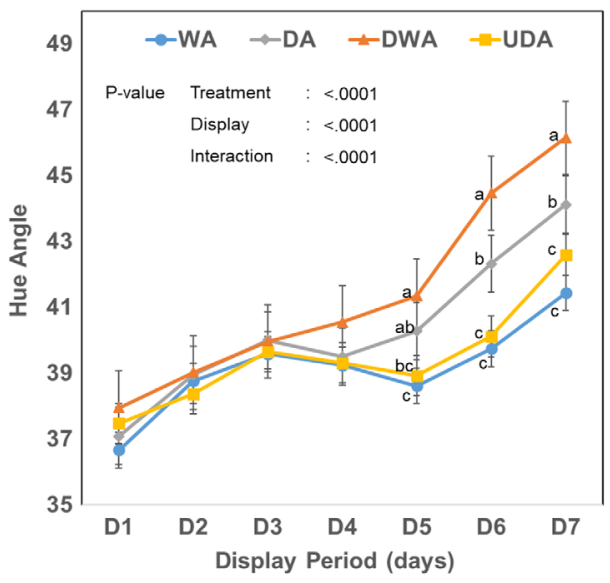

(e) Chroma

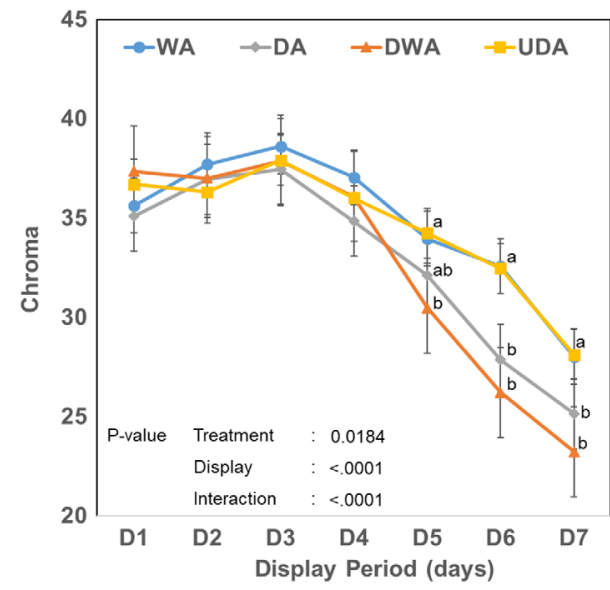

Figure 1. Effect of different aging treatments on instrumental color characteristic changes of cull cow beef $m$. longissimus lumborum during $7 \mathrm{~d}$ of display period. (A) Commission Internationale de 1'Eclairage (CIE) $L^{*}$. (B) CIE $a^{*}$. (C) CIE $b^{*}$. (D) Hue angle. (E) Chroma. DA $=$ conventional dry-aging;

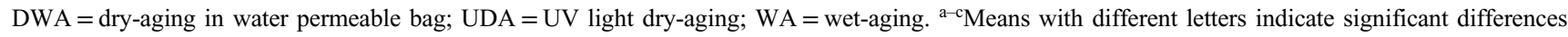
within the same display day $(P<0.05)$.

interaction between treatment and location was observed on all microbial groups measured, indicating different microbial growth patterns in the lean and crust portions (Table 4).
The APC and mold concentration were found to be greater in DWA samples for both crust (6.40 and $5.99 \log _{10} \mathrm{CFU} / \mathrm{mL}$, respectively) and lean (4.80 and $4.65 \log _{10} \mathrm{CFU} / \mathrm{mL}$, respectively) portions compared 
(a) Lean color Score

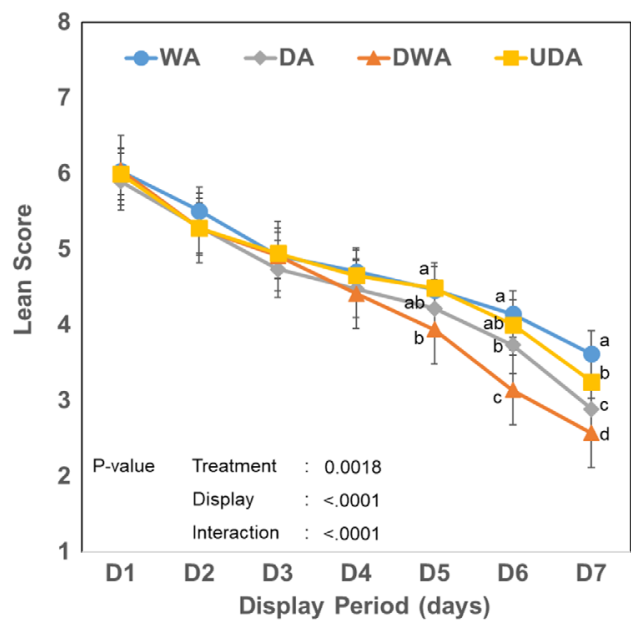

(b) Discoloration Score

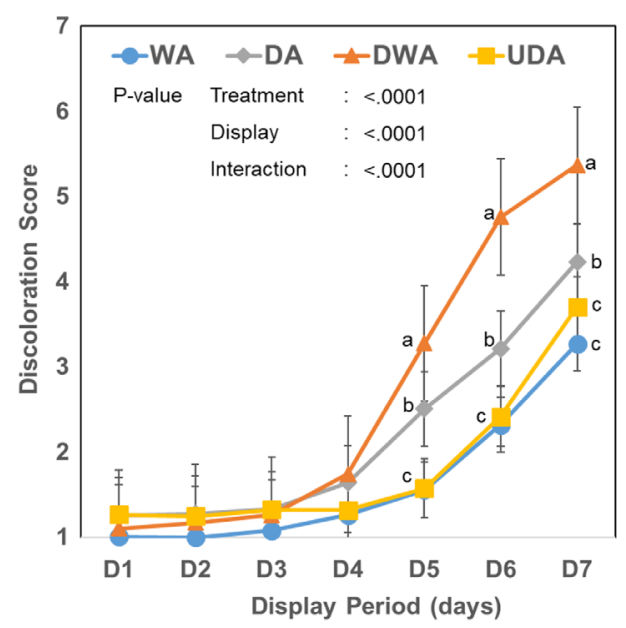

Figure 2. Effect of different aging treatments on visual color characteristic changes of cull cow beef $m$. longissimus lumborum during $7 \mathrm{~d}$ of display period. (A) Lean color score. (B) Discoloration score. DA = conventional dry-aging; DWA = dry-aging in water permeable bag; UDA = UV light dry-aging; $\mathrm{WA}=$ wet-aging. ${ }^{\mathrm{a}-\mathrm{d}}$ Means with different letters indicate significant differences $(P<0.05)$.

Table 3. Effect of different aging treatments on thiobarbituric acid reactive substance (TBARS) and carbonyl content before and after $7 \mathrm{~d}$ of color display on cull cow beef $m$. longissimus lumborum aged for $28 \mathrm{~d}$

\begin{tabular}{|c|c|c|c|c|}
\hline \multirow[b]{2}{*}{ Treatments } & \multicolumn{2}{|c|}{$\begin{array}{c}\text { TBARS }(\mathrm{mg} \\
\text { malondialdehyde } / \mathrm{kg} \\
\text { of meat) }\end{array}$} & \multicolumn{2}{|c|}{$\begin{array}{l}\text { Carbonyl Content } \\
\text { (nmol/mg Protein) }\end{array}$} \\
\hline & D1 & D7 & D1 & D7 \\
\hline WA & 0.944 & 1.373 & 9.344 & 15.690 \\
\hline DA & 1.007 & 1.391 & 9.672 & 14.471 \\
\hline DWA & 1.039 & 1.375 & 9.042 & 14.557 \\
\hline UDA & 0.979 & 1.421 & 9.063 & 17.254 \\
\hline $\begin{array}{l}\text { Standard error } \\
\text { of mean }\end{array}$ & 0.059 & 0.039 & 0.997 & 1.421 \\
\hline$P$ value & 0.457 & 0.250 & 0.727 & 0.068 \\
\hline
\end{tabular}

Different aging treatments: $\mathrm{DA}=$ conventional dry-aging; DWA $=$ dryaging in water permeable bag; UDA $=$ ultraviolet light dry-aging; WA = wet-aging.

with all other treatments $(\mathrm{P}<0.05)$. WA samples had the greatest concentrations of LAB in both crust (5.90 $\left.\log _{10} \mathrm{CFU} / \mathrm{mL}\right)$ and lean $\left(3.79 \log _{10} \mathrm{CFU} / \mathrm{mL}\right)$ portions compared with other treatments $(\mathrm{P}<0.05)$. The yeast was only detected in the crust portion of DWA and WA samples, in which DWA had greater yeast concentrations compared with WA samples $(\mathrm{P}<$ $0.05)$. For the lean, DA samples had a higher yeast count compared with WA samples $(\mathrm{P}<0.05)$. No yeast was detected in the lean portion of DWA and UDA samples. Across all treatments, UDA crust consistently had a lower concentration of microbial groups compared with all other treatments $(\mathrm{P}<0.05)$.
The LAB concentrations were greater in WA samples for both the interior and surface portion, which would be likely due to an anaerobic environment preferred by the LAB (Ahnström et al., 2006). Among the dry-aging treatments, DWA was identified to possess the highest microbial load in the crust and more APC and mold concentration within the lean portion. A similar result was also observed for beef samples packaged in dry-aging bags, where greater concentrations of microbial were found in both the lean (Berger et al., 2018) and crust portions (DeGeer et al., 2009). It was surmised that the utilization of dry-aging bag hindered the crust formation, generating an environment suited for more microbial growth (Berger et al., 2018; DeGeer et al., 2009). The excessive microbial presence and growth in meat could potentially lead to a shorter shelf life of the product. Previous studies showed that higher microbial concentrations induce more discoloration in meat during display (Li et al., 2013), which could be possibly related to the extent of discoloration and color stability observed in the DWA samples in the current study.

In general, greater microbial concentrations were detected on the crusts of all samples compared with the inner portion, with the exception of UDA samples. This result was expected, as microbes are commonly found on the surfaces of the dry-aged meat. In the UDA treatment, however, the UV light application clearly suppressed the growth of microbes. This observation suggests that the UV light can be applied as an affordable and practical intervention method to minimize microbial presence in dry-aged meat. However, while UV light application could be beneficial for food, 
Table 4. Effect of different aging treatments on total aerobic bacteria (APC), lactic acid bacteria (LAB), mold and yeast concentration on crust (surface) and lean portion of cull cow beef $m$. longissimus lumborum after $28 \mathrm{~d}$ of aging

\begin{tabular}{|c|c|c|c|c|c|}
\hline Location & Treatment & $\begin{array}{c}\text { APC }(\log 10 \\
\text { CFU/mL of Rinsate) }\end{array}$ & $\begin{array}{c}\text { LAB ( } \log 10 \\
\text { CFU/mL of Rinsate) }\end{array}$ & $\begin{array}{c}\text { Mold ( } \log 10 \\
\text { CFU/mL of Rinsate) }\end{array}$ & $\begin{array}{c}\text { Yeast ( } \log 10 \\
\text { CFU/mL of Rinsate) }\end{array}$ \\
\hline \multirow[t]{4}{*}{ Lean } & WA & $3.90^{\mathrm{c}}$ & $3.79^{\mathrm{c}}$ & $2.23^{\mathrm{e}}$ & $1.81^{\mathrm{c}}$ \\
\hline & DA & $3.79^{\mathrm{c}}$ & $3.15^{\mathrm{d}}$ & $3.34^{\mathrm{c}}$ & $3.95^{\mathrm{ab}}$ \\
\hline & DWA & $4.80^{\mathrm{b}}$ & $3.14^{\mathrm{d}}$ & $4.65^{\mathrm{b}}$ & $\mathrm{BDL}$ \\
\hline & UDA & $3.84^{\mathrm{c}}$ & $2.78^{\mathrm{d}}$ & $2.81^{\mathrm{d}}$ & $\mathrm{BDL}$ \\
\hline \multirow[t]{4}{*}{ Crust } & WA & $5.96^{\mathrm{a}}$ & $5.90^{\mathrm{a}}$ & $3.75^{\mathrm{c}}$ & $3.29^{\mathrm{b}}$ \\
\hline & DA & $3.95^{\mathrm{c}}$ & $1.88^{\mathrm{e}}$ & $3.33^{\mathrm{c}}$ & $\mathrm{BDL}$ \\
\hline & DWA & $6.40^{\mathrm{a}}$ & $5.23^{\mathrm{b}}$ & $5.99^{\mathrm{a}}$ & $4.43^{\mathrm{a}}$ \\
\hline & UDA & $2.24^{\mathrm{d}}$ & $1.84^{\mathrm{e}}$ & $1.82^{\mathrm{e}}$ & $\mathrm{BDL}$ \\
\hline Standard error of mean & 0.27 & 0.28 & 0.19 & 0.49 & \\
\hline \multirow[t]{3}{*}{$P$ value } & Treatment & $<0.0001$ & $<0.0001$ & $<0.0001$ & 0.0032 \\
\hline & Location & 0.0066 & 0.0027 & 0.0023 & 0.0016 \\
\hline & Interaction & $<0.0001$ & $<0.0001$ & $<0.0001$ & $<0.0001$ \\
\hline
\end{tabular}

${ }^{\mathrm{a}-\mathrm{e}}$ Different superscript letters indicate a significant difference between the different aging methods $(P<0.05)$.

$\mathrm{BDL}=$ below detection limit.

Different aging treatments: $\mathrm{DA}=$ conventional dry-aging; DWA = dry-aging in water permeable bag; UDA = ultraviolet light dry-aging; WA = wet-aging.

sterilization of the exposed surface of meat may affect meat palatability, as the presence of some bacteria and mold may be associated with development of dry-aged beef palatability. Previous reports showed that the presence of mold during aging liberated more free amino acids in the dry-aged product, affecting the flavor potential of the product (Hanagasaki and Asato, 2018; Lee et al., 2019). Both bacteria and mold are well known to have proteolytic and lipolytic activity, which could then enhance the production of flavor precursor through protein and lipid degradation, contributing to the development of unique dry-aged flavor. Further research, therefore, is still needed to fully understand the function and effects of different microbial groups and species on dry-aged flavor development.

\section{Demographic and survey data}

The demographic information of the consumer panel is presented in Table 5. When consuming meat, $76.2 \%$ of the participants preferred beef products compared with other meat products, and $76.9 \%$ of participants reported consuming beef 1-5 times/week. Participants were split for the most important palatability attribute when eating beef steak, with $46.2 \%$ selecting tenderness and $42.3 \%$ selecting flavor. Most of the participants in the study preferred their beef steak cooked to Medium-Rare (35.4\%), followed by Medium-Well (26.2\%) and Medium (22.3\%) doneness.

After evaluating the samples, the panelists were given a series of questions regarding dairy cattle beef, dry-aging, and their willingness to pay for the product (Table 6). Only $39.2 \%$ of the consumer were familiar with dairy beef or cull cow beef; however, $62.8 \%$ of participants reported having a positive perception of dairy beef or cull cow beef. Of all the panelists, $44.6 \%$ had previously consumed dry-aged beef products. Of those participants who had consumed dry-aged beef, $43.3 \%$ reported obtaining dry-aged beef in a restaurant, while $43.1 \%$ reported obtaining dry-aged beef from a local butcher or supermarket. The postmortem meat aging process itself was perceived as a positive term by the majority of the participants (86.9\%). About $39.2 \%$ of the panelists were not sure about the safety of dry-aged beef product, while $37 \%$ of participants perceived the safety of dry-aged as similar to other beef products, $16.2 \%$ of participants perceived it as safer, and $6.9 \%$ perceived it as less safe compared with other beef products. When asked about willingness to pay for dry-aged beef product, $59.2 \%$ of the consumers were willing to pay $\$ 1.00$ more per $1 \mathrm{lb}(0.45 \mathrm{~kg})$ of dry-aged beef. The willingness slightly decreased to $50 \%$ if the dry-aged beef originated from dairy beef.

The current results indicated that while tenderness is an important factor for beef palatability, consumers are now also starting to consider the flavor aspects of beef products at almost an equivalent level. It was previously reported that when tenderness was held constant, flavor became the second most important factor influencing beef satisfaction (Killinger et al., 2004). As most fresh beef currently have acceptable tenderness due to branding requirements and longer postmortem 
Table 5. Demographic characteristics of consumers $(n=130)$ participated in the consumer sensory panels.

\begin{tabular}{|c|c|c|}
\hline $\begin{array}{l}\text { Demographic } \\
\text { Questions }\end{array}$ & $\begin{array}{l}\text { Response } \\
\text { Options }\end{array}$ & $\begin{array}{l}\text { Frequency } \\
(\%)\end{array}$ \\
\hline \multirow[t]{2}{*}{ Gender } & Male & 50.0 \\
\hline & Female & 50.0 \\
\hline \multirow[t]{6}{*}{ Household size } & 1 & 11.5 \\
\hline & 2 & 37.7 \\
\hline & 3 & 12.3 \\
\hline & 4 & 19.2 \\
\hline & 5 & 13.9 \\
\hline & 6 & 5.4 \\
\hline \multirow[t]{2}{*}{ Marital status } & Single & 35.4 \\
\hline & Married & 64.6 \\
\hline \multirow[t]{6}{*}{ Age } & $<20$ years old & 4.6 \\
\hline & $20-29$ years old & 14.6 \\
\hline & 20-39 years old & 23.9 \\
\hline & $40-49$ years old & 17.7 \\
\hline & $50-59$ years old & 20.0 \\
\hline & $>60$ years old & 19.2 \\
\hline \multirow[t]{7}{*}{ Ethnic origin } & African-American & 10.0 \\
\hline & Asian & 0.0 \\
\hline & Caucasian & 56.2 \\
\hline & Hispanic & 29.2 \\
\hline & Native American & 0.0 \\
\hline & Mixed race & 1.5 \\
\hline & Other & 3.1 \\
\hline \multirow{8}{*}{$\begin{array}{l}\text { Annual household } \\
\text { income }\end{array}$} & $<\$ 25,000$ & 7.7 \\
\hline & $\$ 25,000-\$ 34,000$ & 14.6 \\
\hline & $\$ 35,000-\$ 49.999$ & 21.5 \\
\hline & $\$ 50,000-\$ 74,000$ & 20.0 \\
\hline & $\$ 75,000-\$ 99,000$ & 12.3 \\
\hline & $\$ 100,000-\$ 149,000$ & 18.5 \\
\hline & $\$ 150,000-\$ 199,999$ & 3.1 \\
\hline & $>\$ 199,999$ & 2.3 \\
\hline \multirow[t]{5}{*}{$\begin{array}{l}\text { Highest level of } \\
\text { education completed }\end{array}$} & $\begin{array}{l}\text { Non-high school } \\
\text { graduate }\end{array}$ & 0.0 \\
\hline & High school graduate & 22.3 \\
\hline & $\begin{array}{l}\text { Some college/technical } \\
\text { school }\end{array}$ & 39.2 \\
\hline & College graduate & 26.9 \\
\hline & $\begin{array}{l}\text { Post-college } \\
\text { graduate }\end{array}$ & 11.5 \\
\hline \multirow{3}{*}{$\begin{array}{l}\text { When eating beef, what } \\
\text { palatability trait is the } \\
\text { most important to you? }\end{array}$} & Flavor & 42.3 \\
\hline & Juiciness & 11.5 \\
\hline & Tenderness & 46.2 \\
\hline \multirow{7}{*}{$\begin{array}{l}\text { When eating beef steaks, } \\
\text { what degree of doneness } \\
\text { do you prefer? }\end{array}$} & Very rare & 2.3 \\
\hline & Rare & 4.6 \\
\hline & Medium-rare & 35.4 \\
\hline & Medium & 22.3 \\
\hline & Medium-well & 26.2 \\
\hline & Well-done & 7.7 \\
\hline & Very well-done & 1.5 \\
\hline
\end{tabular}

Table 5. (Continued)

\begin{tabular}{lcc}
\hline $\begin{array}{l}\text { Demographic } \\
\text { Questions }\end{array}$ & Response & Frequency \\
Options & $(\%)$ \\
\hline What is your preferred & Beef & 76.2 \\
meat product for flavor? & Chicken & 13.1 \\
& Fish & 2.3 \\
& Lamb & 0.8 \\
& Mutton & 0.0 \\
& Pork & 2.3 \\
& Shellfish & 2.3 \\
& Turkey & 0.8 \\
& Veal & 0.0 \\
How many times per & Venison & 2.3 \\
week do you consume & $1-5$ times/week & 76.9 \\
beef? & $6-10$ times/week & 13.9 \\
& $11-15$ times/week & 7.7 \\
& $>16$ times/week & 1.5 \\
\hline
\end{tabular}

Table 6. Consumer panelist perceptions on dairy cow, dry-aging, and willingness to pay $(\mathrm{n}=130)$

\begin{tabular}{lcc}
\hline \hline End Survey Questions & Response Options & Frequency (\%) \\
\hline Are you familiar with beef & Yes & 39.2 \\
from dairy cattle? & No & 60.8 \\
Do you perceive beef from & Positive & 62.8 \\
dairy cattle as positive or & Negative & 2.0 \\
negative? & Not sure & 35.3 \\
Have you ever eaten dry- & Yes & 44.6 \\
aged beef? & No & 24.6 \\
& Not sure & 30.8 \\
If you have eaten dry-aged & Restaurant & 48.3 \\
beef, where did you purchase & Local butcher store & 17.2 \\
the product from? & Local retail/supermarket & 25.9 \\
& Others & 8.6 \\
Is aging a positive or & Positive & 86.9 \\
negative term? & Negative & 13.1 \\
Do you think dry-aged beef & Safer & 16.2 \\
is safe? & Less safe & 6.9 \\
& Same as other beef & 37.7 \\
Would you be willing to pay & Not sure & 39.2 \\
\$1.00 more per 1 lb for dry- & Yes & 59.2 \\
aged beef? & No & 40.8 \\
Would you be willing to pay & Yes & 50.0 \\
\$1.00 more per 1 lb for dry- & No & 50.0 \\
aged beef from dairy cattle? & & \\
\hline
\end{tabular}

aging application (Martinez et al., 2017), it is possible that consumers are now shifting their focus to flavor, thus explaining the increasing interest in dry-aging process. Compared with a previous study by Berger at al. (2018), a greater percentage of participants reported familiarity with dry-aging process and had consumed dry-aged beef ( $25.8 \%$ compared with $44.6 \%$ in 
Table 7. Effect of different aging treatments on trained panel rating $(\mathrm{n}=11)$ of cull cow beef $m$. longissimus lumborum after 28 days of aging

\begin{tabular}{lccllll}
\hline \hline Traits & WA & DA & DWA & UDA & SEM & $P$ Value \\
\hline Beefy & 46.00 & 47.97 & 47.57 & 48.34 & 1.70 & 0.2863 \\
Brown/roasted & 39.20 & 43.43 & 41.16 & 41.61 & 2.82 & 0.2583 \\
Bloody & 15.36 & 13.13 & 16.65 & 14.65 & 2.16 & 0.2743 \\
Fat & $17.41^{\mathrm{a}}$ & $15.08^{\mathrm{b}}$ & $14.63^{\mathrm{b}}$ & $15.60^{\mathrm{b}}$ & 1.17 & 0.0301 \\
Liver & 6.87 & 5.40 & 5.71 & 5.04 & 0.71 & 0.239 \\
Oxidized & 4.50 & 3.72 & 4.35 & 5.52 & 0.57 & 0.0767 \\
Metallic & 8.87 & 7.60 & 8.25 & 8.27 & 0.60 & 0.2934 \\
Fishy & 6.83 & 5.77 & 6.35 & 5.96 & 0.75 & 0.7218 \\
Buttery & 11.35 & 10.07 & 8.42 & 8.89 & 1.14 & 0.226 \\
Nutty & 8.57 & 8.32 & 7.43 & 8.44 & 0.98 & 0.7563 \\
Earthy & 14.14 & 14.50 & 14.37 & 14.33 & 1.19 & 0.996 \\
Umami & 14.28 & 14.82 & 14.23 & 14.12 & 0.87 & 0.9102 \\
Salty & 3.45 & 3.33 & 4.29 & 4.15 & 0.66 & 0.2057 \\
Bitter & 3.15 & 2.68 & 2.76 & 2.83 & 0.42 & 0.7395 \\
Sour & $6.14^{\mathrm{a}}$ & $4.43^{\mathrm{b}}$ & $5.29^{\mathrm{ab}}$ & $6.15^{\mathrm{a}}$ & 0.45 & 0.0113 \\
Overall juiciness & $63.30^{\mathrm{a}}$ & $57.46^{\mathrm{b}}$ & $58.56^{\mathrm{b}}$ & $57.91^{\mathrm{b}}$ & 1.49 & 0.0067 \\
Overall tenderness & 60.31 & 60.76 & 60.65 & 57.28 & 1.81 & 0.2053 \\
\hline
\end{tabular}

${ }^{\mathrm{a}, \mathrm{b}}$ Different superscript letters indicate a significant difference between the different aging methods $(P<0.05)$.

$\mathrm{SEM}=$ standard error of mean

Different aging treatments: $\mathrm{DA}=$ conventional dry-aging; DWA $=$ dry-aging in water permeable bag; $\mathrm{UDA}=$ ultraviolet light dry-aging; $\mathrm{WA}=$ wet-aging.

the current study). While it could potentially be due to survey location differences, the growing interest in dryaged beef could potentially reflect the survey results, as more consumers seek flavor-enhanced fresh beef products (Campbell et al., 2001; Kim et al., 2016; O’Quinn et al., 2016).

\section{Sensory panel evaluation}

Overall, results from the consumer panel showed that different aging methods resulted in similar sensory attributes $(\mathrm{P}>0.05$, Table 8$)$. Consumers rated similar scores in flavor, tenderness, juiciness, and overall liking for steak samples from the different aging methods. Similarly, when asked for the acceptability of each trait, consumers found the majority of the products to be acceptable regardless of the aging treatments $(\mathrm{P}>$ $0.05)$. When requested to select perceived flavor from a preselected list, a greater percentage of participants assigned a beefy flavor of WA and DWA samples compared with DA and UDA $(\mathrm{P}<0.05)$. No significant difference was found for all other flavor attributes across all treatments $(\mathrm{P}>0.05)$.

For the trained sensory panel evaluation, however, a significant treatment effect was found in fat-like
Table 8. Effect of different aging treatments on consumer sensory panel $(\mathrm{n}=130)$ likeness, acceptability, perceived quality, and perceived flavor of cull cow beef $m$. longissimus lumborum after $28 \mathrm{~d}$ of aging

\begin{tabular}{|c|c|c|c|c|c|c|}
\hline Traits & WA & DA & DWA & UDA & SEM & $\begin{array}{c}P \\
\text { Value }\end{array}$ \\
\hline \multicolumn{7}{|l|}{ Likeness } \\
\hline Flavor & 60.24 & 61.50 & 62.78 & 61.39 & 4.28 & 0.9371 \\
\hline Tenderness & 61.98 & 64.45 & 66.79 & 65.31 & 3.56 & 0.5948 \\
\hline Juiciness & 65.38 & 64.89 & 68.42 & 68.01 & 3.17 & 0.6575 \\
\hline Overall & 60.53 & 60.84 & 62.72 & 60.47 & 3.84 & 0.9311 \\
\hline \multicolumn{7}{|l|}{ Acceptability (\%) } \\
\hline $\begin{array}{l}\text { Tenderness } \\
\text { acceptability }\end{array}$ & 83.92 & 85.73 & 85.98 & 84.57 & 4.16 & 0.9620 \\
\hline Juiciness acceptability & 89.81 & 89.83 & 91.95 & 85.47 & 4.56 & 0.3720 \\
\hline Flavor acceptability & 82.62 & 84.71 & 98.50 & 81.05 & 4.66 & 0.8830 \\
\hline Overall acceptability & 83.80 & 84.87 & 83.98 & 81.25 & 5.06 & 0.8752 \\
\hline \multicolumn{7}{|l|}{ Perceived Quality (\%) } \\
\hline Unsatisfactory quality & 13.85 & 14.90 & 14.51 & 16.49 & 4.94 & 0.9408 \\
\hline Everyday quality & 45.13 & 39.85 & 38.11 & 43.61 & 4.53 & 0.6501 \\
\hline $\begin{array}{l}\text { Better than everyday } \\
\text { quality }\end{array}$ & 29.10 & 32.52 & 26.63 & 24.27 & 4.51 & 0.5073 \\
\hline Premium quality & 9.52 & 10.03 & 18.05 & 13.00 & 3.39 & 0.1597 \\
\hline \multicolumn{7}{|l|}{$\begin{array}{l}\text { Check All that Apply } \\
\text { Flavor (\%) }\end{array}$} \\
\hline Beefy & $80.47^{\mathrm{a}}$ & $66.90^{\mathrm{b}}$ & $78.356^{\mathrm{a}}$ & $67.95^{\mathrm{b}}$ & 4.35 & 0.0282 \\
\hline Brown/roasted & 16.41 & 15.31 & 12.52 & 19.66 & 4.84 & 0.4782 \\
\hline Nutty & 4.94 & 6.81 & 5.29 & 5.98 & 2.21 & 0.9188 \\
\hline Buttery & 10.35 & 13.23 & 16.17 & 15.43 & 3.25 & 0.5290 \\
\hline Sour & 3.63 & 3.09 & 3.85 & 3.02 & 1.55 & 0.9723 \\
\hline Metal & 6.65 & 5.47 & 6.44 & 3.58 & 2.37 & 0.6977 \\
\hline Rancid & 1.24 & 0.64 & 2.00 & 4.50 & 1.20 & 0.1627 \\
\hline Other & 3.76 & 7.19 & 4.73 & 9.90 & 3.62 & 0.1538 \\
\hline
\end{tabular}

${ }^{\mathrm{a}, \mathrm{b}}$ Different superscript letters indicate a significant difference between the different aging methods $(P<0.05)$.

$\mathrm{SEM}=$ standard error of mean.

Different aging treatments: DA $=$ conventional dry-aging; DWA $=$ dryaging in water permeable bag; UDA = ultraviolet light dry-aging; WA = wet-aging.

flavor, sour flavor, and overall juiciness $(\mathrm{P}<0.05$, Table 7). Greater fat-like flavor and overall juiciness were observed in the WA samples compared with all dry-aged treatments $(\mathrm{P}<0.05)$. Both WA and UDA samples were more sour, while DA samples were the least sour $(\mathrm{P}<0.05)$. The DWA loins were not different in sourness when compared with all the treatments $(\mathrm{P}>0.05)$. Samples from UDA tended to have greater oxidized flavor among all the treatments $(\mathrm{P}=0.0767)$.

Generally, beef originated from older animal tends to have more intense flavor (Stelzleni et al., 2007). In the current study, a greater percentage of WA and DWA samples were rated beefy by consumers when 
compared with the DA and UDA samples. The trained panelists, however, did not find any discernable differences in beefy flavor among treatments. This could potentially indicate that the consumer description of beefy flavor might be different from the beefy flavor described by the trained panelist. It is possible that the beefy flavor the consumer perceived is more related to the WA process, since they are more accustomed to the product, which could then lead to higher beefy ratings for WA and DWA loins. Moreover, it is important to note that DA samples resulted in a decrease in sour flavor compared with WA and DWA samples, indicating conventional dry-aging effectively diminished one of the major off-flavor attributes of mature cull cow beef.

The increase in juiciness could potentially be attributed to greater moisture retention in WA following the aging process. However, it is not clear why lower fat-like flavor was observed in all dry-aged treatments since greater fat content was observed in actual dry-aged samples. The fat flavor is often associated with the species-specific flavor that identifies meat as beef and is related to the cooked beef fat aromatic (Nollet et al., 2012). While it might be desirable, the increase of this flavor might not be beneficial in mature cow product. As previous reports indicated, mature cow beef often has an intense flavor resulting from increased physiological age and the extended pasture diet (Woerner, 2010; Corbin et al., 2015). It is possible that the intense flavor from both the meat and fat portion generated an overwhelming flavor, making the flavor undesirable for the consumer.

\section{Conclusions}

The results of the current study indicated that dryaging could be utilized as a natural value-adding process for mature cow beef by improving the eating quality with minimal negative impact. The application of DA could potentially increase the product quality by minimizing the prevalence of negative flavors such as sour, oxidized, and intense animal flavor without any detrimental impact on meat quality. Likewise, the application of UV light limited microbial growth during the aging process with no immediate detrimental impact on meat quality, while there were some trends of increases in oxidized flavor and protein oxidation as well as sour flavor in the product. The usage of dryaging bag, while limiting the processing loss, significantly increased the microbial concentration as well as reduced color stability. Additionally, the consumer survey results confirmed an increase in consumer interest in dry-aging; however, consumers might not be familiar with the actual dry-aged beef flavor. Further research to identify the alteration of chemical compounds following dry-aging and the underlying mechanism of flavor development from the different aging methods would be warranted.

\section{Acknowledgements}

The authors declare they have no conflict of interest with any organization regarding this manuscript. This work was supported in part by Agriculture and Food Research Initiative Grant 2017-67017-26475 from the USDA National Institute of Food and Agriculture. Appreciation is extended to the support of Purdue Meat Laboratory staff and the members of the Meat Science and Muscle Biology Laboratory for the successful completion of the sample and data collection.

\section{Literature Cited}

Adesulu-Dahunsi, A. T., S. O. Dahunsi, and A. Olayanju. 2020. Synergistic microbial interactions between lactic acid bacteria and yeasts during production of Nigerian indigenous fermented foods and beverages. Food Control. 110:106963. https://doi.org/10.1016/j.foodcont.2019.106963.

Ahnström, M. L., M. Seyfert, M. C. Hunt, and D. E. Johnson. 2006. Dry aging of beef in a bag highly permeable to water vapour. Meat Sci. 73:674-679. https://doi.org/10.1016/j.meatsci. 2006.03.006.

AMSA. 2012. Meat color measurement guidelines. American Meat Science Association, Champaign, IL.

AMSA. 2016. Research guidelines for cookery, sensory evaluation, and instrumental tenderness measurements of meat. American Meat Science Association, Champaign, IL.

AOAC. 2007. Official methods of analysis of AOAC International. 18th ed. Second revision. AOAC International, Rockville, MD.

Berger, J., Y. H. B. Kim, J. F. Legako, S. Martini, J. Lee, P. Ebner, and S. M. S. Zuelly. 2018. Dry-aging improves meat quality attributes of grass-fed beef loins. Meat Sci. 145:285-291. https://doi.org/10.1016/j.meatsci.2018.07.004.

Campbell, R. E., M. C. Hunt, P. Levis, and E. Chambers IV. 2001. Dry-aging effects on palatability of beef longissimus muscle. J. Food Sci. 66:196-199. https://doi.org/10.1111/j.13652621.2001.tb11315.x.

Choe, J., B. Park, H. J. Lee, and C. Jo. 2020. Potential antioxidant and angiotensin I-converting enzyme inhibitory activity in crust of dry-aged beef. Sci. Rep.-UK. 10:7883. https://doi. org/10.1038/s41598-020-64861-0.

Chun, H. H., J. Y. Kim, B. D. Lee, D. J. Yu, and K. B. Song. 2010. Effect of UV-C irradiation on the inactivation of inoculated pathogens and quality of chicken breasts during storage. 
Food Control. 21:276-280. https://doi.org/10.1016/j.foodcont. 2009.06.006.

Corbin, C. H., T. G. O’Quinn, A. J. Garmyn, J. F. Legako, M. R. Hunt, T. T. N. Dinh, R. J. Rathmann, J. C. Brooks, and M. F. Miller. 2015. Sensory evaluation of tender beef strip loin steaks of varying marbling levels and quality treatments. Meat Sci. 100:24-31. https://doi.org/10.1016/j.meatsci.2014. 09.009.

DeGeer, S. L., M. C. Hunt, C. L. Bratcher, B. A. Crozier-Dodson, D. E. Johnson, and J. F. Stika. 2009. Effects of dry aging of bone-in and boneless strip loins using two aging processes for two aging times. Meat Sci. 83:768-774. https://doi.org/10. 1016/j.meatsci.2009.08.017.

Dikeman, M. E., E. Obuz, V. Gök, L. Akkaya, and S. Stroda. 2013. Effects of dry, vacuum, and special bag aging; USDA quality grade; and end-point temperature on yields and eating quality of beef Longissimus lumborum steaks. Meat Sci. 94:228-233. https://doi.org/10.1016/j.meatsci.2013.02.002.

Diles, J. J. B., M. F. Miller, and B. L. Owen. 1994. Calcium chloride concentration, injection time, and aging period effects on tenderness, sensory, and retail color attributes of loin steaks from mature cows. J. Anim. Sci. 72:2017-2021. https://doi.org/10. 2527/1994.7282017x.

Ganan, M., E. Hierro, X. F. Hospital, E. Barroso, and M. Fernández. 2013. Use of pulsed light to increase the safety of ready-to-eat cured meat products. Food Control. 32:512-517. https://doi. org/10.1016/j.foodcont.2013.01.022.

Gredell, D. A., T. G. O'Quinn, J. F. Legako, J. C. Brooks, and M. F. Miller. 2018. Palatability and biochemical factors of beef from mature cattle finished on a concentrate diet prior to harvest. Meat Muscle Biol. 2:111-126. https://doi.org/10.22175/ mmb2017.09.0046.

Hanagasaki, T., and N. Asato. 2018. Changes in free amino acids and hardness in round of Okinawan delivered cow beef during dry- and wet-aging processes. J. Anim. Sci. Technol. 60:23. https://doi.org/10.1186/s40781-018-0180-x.

Horiuchi, H., and Y. Sasaki. 2012. Short communication: Effect of oxygen on symbiosis between Lactobacillus bulgaricus and Streptococcus thermophilus. J. Dairy Sci. 95:2904-2909. https://doi.org/10.3168/jds.2011-5147.

Jongberg, S., M. N. Lund, and L. H. Skibsted. 2017. Protein oxidation in meat and meat products. Challenges for antioxidative protection. In: G. V. Barbosa-Cánocas, G. M. Pastore, K. Candogan, I. G. Medina Meza, S. C. d. S. Lannes, K. Buckles, R. Y. Yada, and A. Rosenthal, editors, Global food security and wellness. Springer, New York. p. 315-337.

Killinger, K. M., C. R. Calkins, W. J. Umberger, D. M. Feuz, and K. M. Eskridge. 2004. Consumer sensory acceptance and value for beef steaks of similar tenderness, but differing in marbling level. J. Anim. Sci. 82:3294-3301. https://doi.org/10.2527/ 2004.82113294x.

Kim, Y. H. B., R. Kemp, and L. M. Samuelsson. 2016. Effects of dry-aging on meat quality attributes and metabolite profiles of beef loins. Meat Sci. 111:168-176. https://doi.org/10.1016/j. meatsci.2015.09.008.

Kim, Y. H. B., D. Ma, D. Setyabrata, M. M. Farouk, S. M. Lonergan, E. Huff-Lonergan, and M. C. Hunt. 2018. Understanding postmortem biochemical processes and postharvest aging factors to develop novel smart-aging strategies.
Meat Sci. 144:74-90. https://doi.org/10.1016/J.MEATSCI. 2018.04.031.

Kim, Y. H. B., B. Meyers, H.-W. Kim, A. M. Liceaga, and R. P. Lemenager. 2017. Effects of stepwise dry/wet-aging and freezing on meat quality of beef loins. Meat Sci. 123:5763. https://doi.org/10.1016/j.meatsci.2016.09.002.

Laster, M. A., R. D. Smith, K. L. Nicholson, J. D. W. Nicholson, R. K. Miller, D. B. Griffin, K. B. Harris, and J. W. Savell. 2008. Dry versus wet aging of beef: Retail cutting yields and consumer sensory attribute evaluations of steaks from ribeyes, strip loins, and top sirloins from two quality grade groups. Meat Sci. 80:795-804. https://doi.org/10.1016/j.meatsci.2008. 03.024 .

Lee, H., M. Jang, S. Park, J. Jeong, Y.-S. Shim, and J.-C. Kim. 2019. Determination of indicators for dry aged beef quality. Food Sci. Anim. Resour. 39:934-942. https://doi.org/10. 5851/kosfa.2019.e83.

Lepper-Blilie, A. N., E. P. Berg, D. S. Buchanan, and P. T. Berg. 2016. Effects of post-mortem aging time and type of aging on palatability of low marbled beef loins. Meat Sci. 112:63-68. https://doi.org/10.1016/j.meatsci.2015.10.017.

Li, X., J. Babol, A. Wallby, and K. Lundström. 2013. Meat quality, microbiological status and consumer preference of beef $g l u$ teus medius aged in a dry ageing bag or vacuum. Meat Sci. 95:229-234. https://doi.org/10.1016/j.meatsci.2013.05.009.

Martinez, H. A., A. N. Arnold, J. C. Brooks, C. C. Carr, K. B. Gehring, D. B. Griffin, D. S. Hale, G. G. Mafi, D. D. Johnson, C. L. Lorenzen, R. J. Maddock, R. K. Miller, D. L. VanOverbeke, B. E. Wasser, and J. W. Savell. 2017. National Beef Tenderness Survey-2015: Palatability and shear force assessments of retail and foodservice beef. Meat Muscle Biol. 1:138-148. https://doi.org/10.22175/mmb2017. 05.0028 .

Moreira, L. C., G. J. M. Rosa, and D. M. Schaefer. 2021. Beef production from cull dairy cows: a review from culling to consumption. J. Anim. Sci. 99:skab192. https://doi.org/10.1093/ jas/skab192.

Morgan, J. B., R. K. Miller, F. M. Mendez, D. S. Hale, and J. W. Savell. 1991. Using calcium chloride injection to improve tenderness of beef from mature cows. J. Anim. Sci. 69:44694476. https://doi.org/10.2527/1991.69114469x.

Nollet, L. M. L., Boylston, T., F. Chen, P. C. Coggins, G. Hydlig, and L. McKee. 2012. Handbook of meat, poultry and seafood quality. Wiley-Blackwell, Hoboken, NJ.

O’Quinn, T. G., D. R. Woerner, T. E. Engle, P. L. Chapman, J. F. Legako, J. C. Brooks, K. E. Belk, and J. D. Tatum. 2016. Identifying consumer preferences for specific beef flavor characteristics in relation to cattle production and postmortem processing parameters. Meat Sci. 112:90-102. https://doi.org/ 10.1016/j.meatsci.2015.11.001.

Obuz, E., L. Akkaya, V. Gök, and M. E. Dikeman. 2014. Effects of blade tenderization, aging method and aging time on meat quality characteristics of longissimus lumborum steaks from cull Holstein cows. Meat Sci. 96:1227-1232. https://doi. org/10.1016/j.meatsci.2013.11.015.

Ozer, N. P., and A. Demirci. 2006. Inactivation of Escherichia coli O157:H7 and Listeria monocytogenes inoculated on raw salmon fillets by pulsed UV-light treatment. Int. J. Food 
Sci. Tech. 41:354-360. https://doi.org/10.1111/j.1365-2621. 2005.01071.x.

Savell, J. W. 2008. Dry-aging of beef. National Cattlemen's Beef Association, Centennial, CO.

Setyabrata, D., B. R. Cooper, T. J. P. Sobreira, J. F. Legako, S. Martini, and Y. H. B. Kim. 2021. Elucidating mechanisms involved in flavor generation of dry-aged beef loins using metabolomics approach. Food Res. Int. 139:109969. https:// doi.org/10.1016/j.foodres.2020.109969.

Setyabrata, D., and Y. H. B. Kim. 2019. Impacts of aging/freezing sequence on microstructure, protein degradation and physicochemical properties of beef muscles. Meat Sci. 151:64-74. https://doi.org/10.1016/J.MEATSCI.2019.01.007.

Smith, A. M., K. B. Harris, D. B. Griffin, R. K. Miller, C. R. Kerth, and J. W. Savell. 2014. Retail yields and palatability evaluations of individual muscles from wet-aged and dry-aged beef ribeyes and top sirloin butts that were merchandised innovatively. Meat Sci. 97:21-26. https://doi.org/10.1016/j.meatsci.2013.12.013.

Smith, R. D., K. L. Nicholson, J. D. W. Nicholson, K. B. Harris, R. K. Miller, D. B. Griffin, and J. W. Savell. 2008. Dry versus wet aging of beef: Retail cutting yields and consumer palatability evaluations of steaks from US Choice and US Select short loins. Meat Sci. 79:631-639. https://doi.org/10.1016/j. meatsci.2007.10.028.

Stelzleni, A. M., L. E. Patten, D. D. Johnson, C. R. Calkins, and B. L. Gwartney. 2007. Benchmarking carcass characteristics and muscles from commercially identified beef and dairy cull cow carcasses for Warner-Bratzler shear force and sensory attributes. J. Anim. Sci. 85:2631-2638. https://doi.org/10.2527/jas. 2006-794.
USDA. 2019. Livestock slaughter: Record high red meat and pork production in November. USDA, Washington, DC.

Verbeke, W., F. J. A. Pérez-Cueto, M. D. d. Barcellos, A. Krystallis, and K. G. Grunert. 2010. European citizen and consumer attitudes and preferences regarding beef and pork. Meat Sci. 84:284-292. https://doi.org/10.1016/j.meatsci.2009.05.001.

Vossen, E., and S. De Smet. 2015. Protein oxidation and protein nitration influenced by sodium nitrite in two different meat model systems. J. Agric. Food Chem. 63:2550-2556. https://doi.org/10.1021/jf505775u.

Warren, K. E., and C. L. Kastner. 1992. A comparison of dry-aged and vacuum-aged beef strip loins. J. Muscle Foods. 3:151157. https://doi.org/10.1111/j.1745-4573.1992.tb00471.x.

Woerner, D. R. 2010. White paper product enhancement research: Beef from market cows. National Cattlemen's Beef Association, Centennial, CO.

Xiong, Y. L., O. E. Mullins, J. F. Stika, J. Chen, S. P. Blanchard, and W. G. Moody. 2007. Tenderness and oxidative stability of post-mortem muscles from mature cows of various ages. Meat Sci. 77:105-113. https://doi.org/10.1016/j.meatsci. 2007.04.012.

Xue, S., D. Setyabrata, C. C. Bonham, and Y. H. B. Kim. 2021. Evaluation of functional and chemical properties of crust from dry-aged beef loins as a novel food ingredient. Meat Sci. 173:108403. https://doi.org/10.1016/j.meatsci.2020.108403.

Yeh, Y., F. H. de Moura, K. Van Den Broek, and A. S. de Mello. 2018. Effect of ultraviolet light, organic acids, and bacteriophage on Salmonella populations in ground beef. Meat Sci. 139:44-48. https://doi.org/10.1016/j.meatsci.2018.01.007. 